\title{
Penile prosthesis implant for erectile dysfunction: A new minimally invasive infrapubic surgical technique
}

\author{
Gabriele Antonini ${ }^{1}$, Gian Maria Busetto ${ }^{1}$, Ettore De Berardinis ${ }^{1}$, Riccardo Giovannone ${ }^{1}$, \\ Patrizio Vicini ${ }^{2}$, Vincenzo Gentile ${ }^{1}$, Paul E. Perito ${ }^{3}$ \\ ${ }^{1}$ Department of Gynecological-Obstetrics Sciences and Urological Sciences, Sapienza Rome University, Policlinico Umberto I, Rome, Italy; \\ 2 Department of Urology, "I.N.I." Italian Neurotraumatologic Institute Grottaferrata, Rome, Italy; \\ ${ }^{3}$ Perito Urology, Coral Gables Hospital Miami, Florida, USA.
}

\begin{abstract}
Summary Erectile dysfunction, the most common male sexual disorder after premature ejaculation, with its important impact on man and partner's sexuality and quality of life is a persistent inability to obtain and maintain an erection sufficient to permit satisfactory sexual performance. Non-surgical treatments with controversial results are usually applyed before surgical treatment that has reached high levels of satisfaction.

We describe a new surgical technique to implant three-pieces penile prosthesis in patients suffering from erectile dysfunction (ED) not responding to conventional medical therapy or reporting side effects with such a therapy.

Implantation of an inflatable prosthesis, for treatment of ED, is a safe and efficacious approach with high satisfaction reported by patients and partners. Surgical technique should be minimally invasive and latest technology equipment should be implanted in order to decrease common complications and to obtain a better aesthetic result.
\end{abstract}

KEY WORDS: Erectile dysfunction; Penile prosthesis; Infrapubic access.

Submitted 17 March; Accepted 30 June

\section{INTRODUCTION}

Erectile dysfunction (ED), the most common male sexual disorder after premature ejaculation, with its important impact on man and partner's sexuality and quality of life is a persistent inability to obtain and maintain an erection sufficient to permit satisfactory sexual performance. The incidence ranges between $2-28.9 \%$ in the age group from $30-39$ to $41.9-83 \%$ in the age group from 70-80 (1-3).

Regarding treatment, to date, first-line approach is performed with the usage of pharmaceuticals such as PDE5 inhibitors and second-line with intracavernous injection (ICI), vacuum devices or intraurethral alprostadil. Medical therapy has a high drop-out rate that is up to $80 \%(4,5)$. Surgical treatment, as third-line therapy, can be performed after failure of all other options. Penile prosthesis implant, although invasive, has reached high levels of satisfaction and is associated with better sexual function, perception and with patient and partner's high gratification $(6,7)$. Complications related to mechanical failure of prosthesis, requiring repair, explants or replacement are: fluid leak from the device, supersonic transport (SST) deformity, cylinder's aneurismal dilatation or extrusion (8). Infections remain the most common and serious surgical complications with the risk of further penile shortening, urethral injury with erosion and tissue loss $(9,10)$. Patients with comorbidities (diabetes, immunosuppression, spinal cord injury, etc.) are usually at increased risk of infectious complications (11). Infectious mechanism is characterized by bacterial implantation on the surface of the device creating a biofilm that avoid the immune system and antibiotics to exert their effect (12). At this time cylinders, pump and tubing of the three-piece IPP are impregnated with antibiotics (rifampicin and minocycline) which have been associated with the reduction in post operative infections (13).

\section{SURGICAL TECHNIQUE}

We report a new surgical technique of penile prosthesis implant in patients suffering from erectile dysfunction not responding to conventional medical therapy or reporting side effects with such a therapy.

All subjects underwent primary penile prosthesis implant and all the procedures had been carried out at Department of Urological Sciences of Sapienza Rome University by a single surgeon. The prostheses were either the AMS 700 CX (AMS, Minnetonka, MN, USA) or the Coloplast Titan ${ }^{\circledR}$ OTR (Coloplast Corporation, Minneapolis, MN, USA) with controlled expansion cylinders optimize girth (14). The AMS prostheses are connected with an AMS Conceal ${ }^{\mathrm{TM}}$ low profile reservoir coated with parylene and are characterized by Momentary Squeeze pump with one-touch button designed for easy deflation and lock-out valve designed to resist auto-inflation; InhibiZone ${ }^{\mathrm{TM}}$ antibiotic treatment (minocycline and rifampicin) creates a zone of inhibition effective against the bacteria commonly associated with inflatable prosthesis infections. The Coloplast prostheses are connected with Coloplast $\operatorname{Titan}^{\circledR}$ CL reservoir with a four-leaf clover shape and are characterized by lock-out ${ }^{\mathrm{TM}}$ safety valve designed to prevent auto-inflation and One Touch Release (OTR) for easy deflation of the device; hydrophilic coating decreases infection risk. The implants were performed by a minimally invasive technique and, after the patient was shaved, the skin 
pepped for 10 minutes with a poviodone-iodine solution and intravenous cefazolin was administered.

The first step is induction of an artificial erection that allows to identify any pathology needing correction, verifies "true" dilation of the corpora supplanting serial dilations and facilitates the identification of the dorsal nerve and lateral placement of stay sutures. An infrapubic $3 \mathrm{~cm}$ skin incision followed by $1.5 \mathrm{~cm}$ bilateral corporotomy incision is applied (Figures 1, 2).

Using the Furlow, the proximal and distal corpora cavernosa are measured and dilated (Figures 3, 4).

We place color-coded stay sutures in the corpora, lateral to the dorsal nerve. Using a 31/2 inch nasal speculum a

\section{Figure 1.}

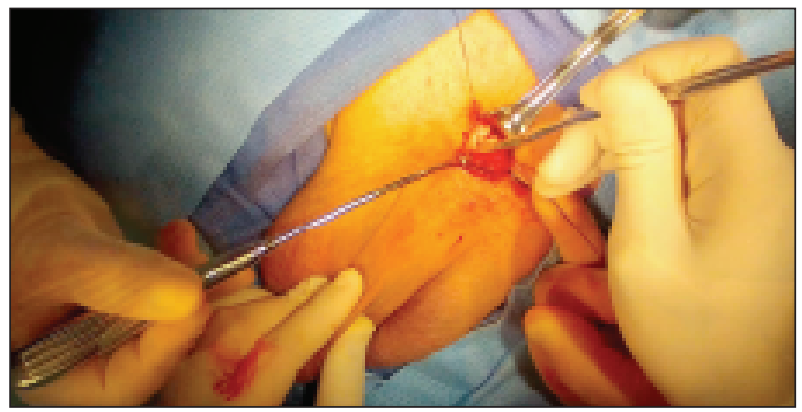

Figure 2.

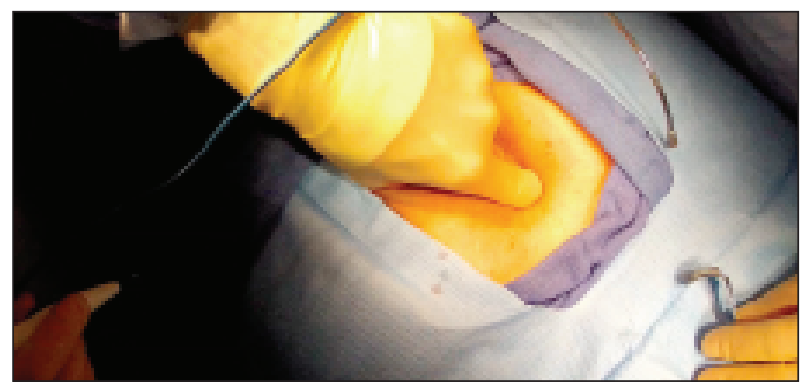

Figure 3.

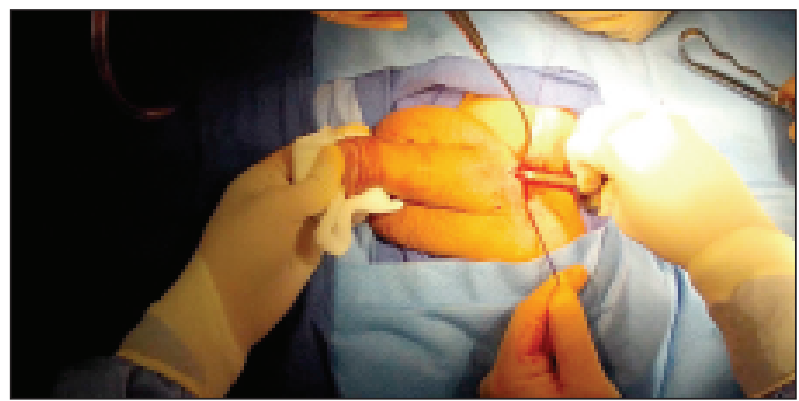

Figure 4.

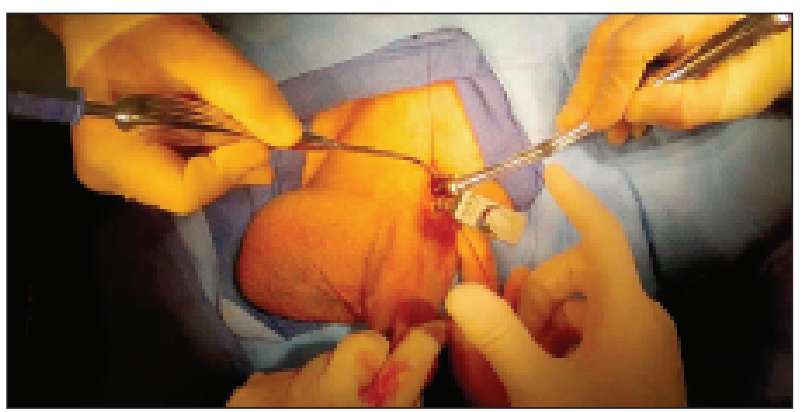

Figure 5.

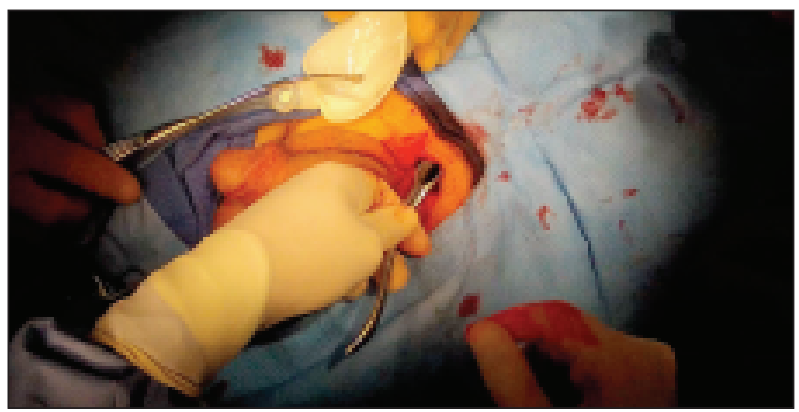

Figure 6.

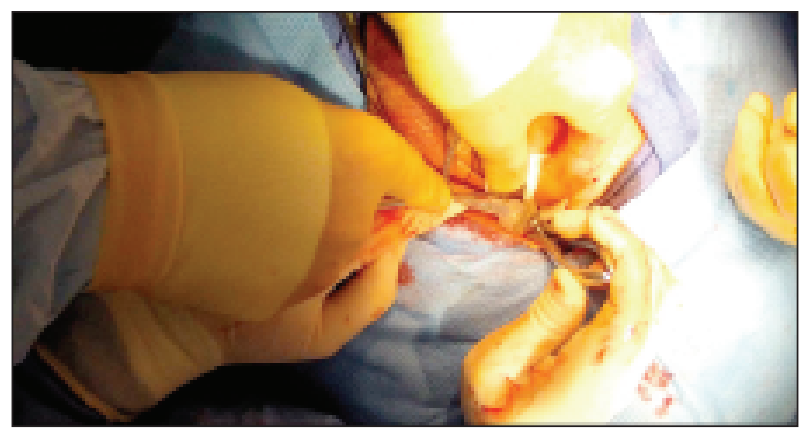

Figure 7.

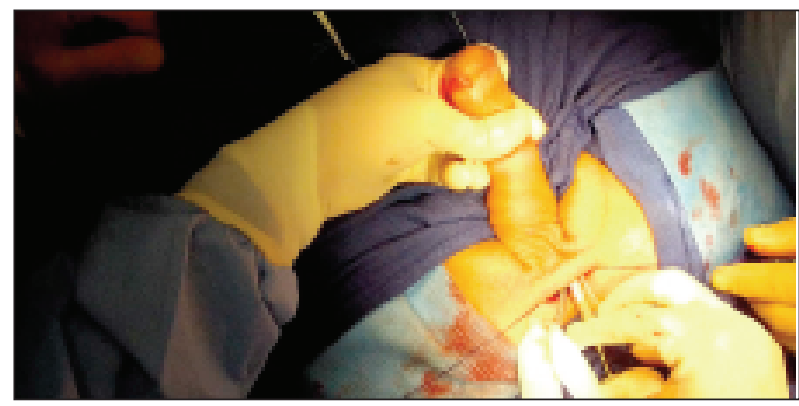

Figure 8.

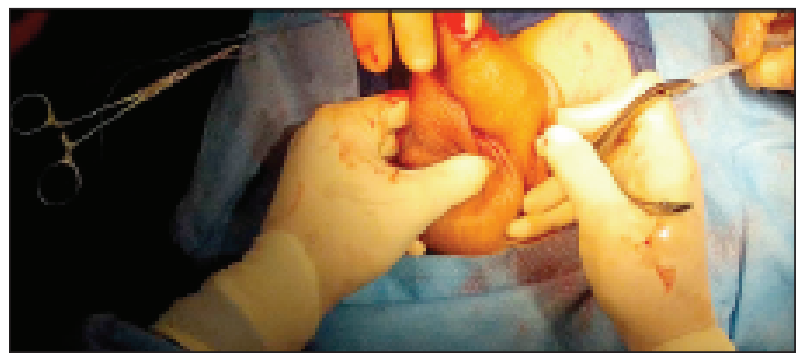

space for the reservoir (filled with $100 \mathrm{~mL}$ of saline solution), posterior to transversalis fascia in cephalad to caudal position (Figures 5, 6), is created.

After exposure, cylinders are placed using stay sutures for retraction and functional/cosmetic result are checked by rapidly inflating the prosthesis (Figure 7).

Once again, the nasal speculum is utilized, this time, to develop the subdartos pouch into dependant portion of scrotum (Figure 8).

After performing the hydraulic test (Figure 9) we finally close the corporotomies using the stay suture previously placed. We then connect the appropriate tubing and a Jackson-Pratt drain is placed in dependent portion of 


\section{Figure 9.}

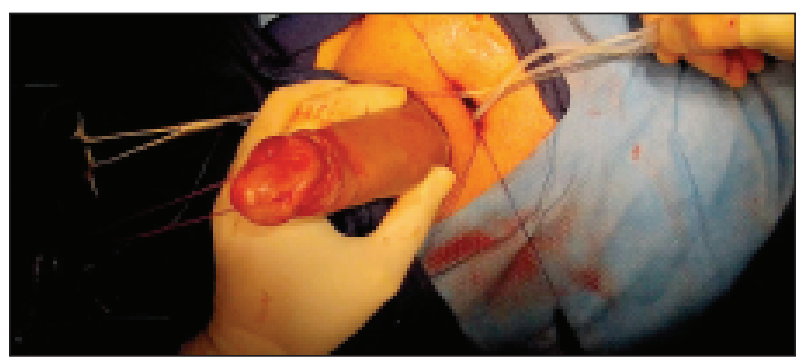

Figure 10.

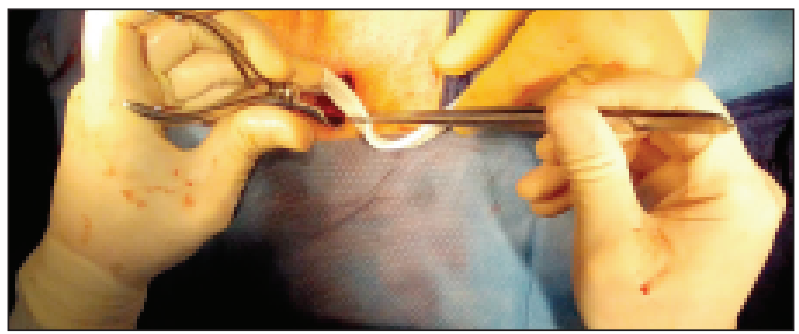

scrotum (Figure 10) and skin incision closed with subcuticular sutures (15). There were no reported intraoperative complications and the median time to complete the implant was 39 min (26-74). Following the implant regular follow-up controls were scheduled; the first activation of the prosthesis is applied 8-10 days after the implantation and the patient starts sexual intercourse after 6 weeks. After surgery ten days of cefazolin and a single dose of gentamycin are administered.

All treatments applied are part of routine standard care and the surgical technique was conducted in line with European Urology and Good Clinical Practice guidelines, with ethical principles laid down in the latest version of the Declaration of Helsinki. Every patient has been informed and signed the consent. In accordance with literature data, patients satisfaction and QoL is better after implant of a three-pieces device because inflatable penile prostheses are characterized by improved flaccidity and rigidity and are usually preferred because of the more "natural" erection obtained (16-18). Bernal et al. in a meta-analyzed 20 years of literature reached the conclusion that despite the variability of used methods and lack of approved questionnaire, patients are satisfied with the implant and with the subsequent sexual activity (19). Moskovic et al. analyzed partners satisfaction concluding that male satisfaction correlate positively with female's one, while unsatisfied men have a relation with female suffering from sexual activity quality (20).

We can conclude that our technique is very fast, safe and the aesthetic result is guaranteed with a small skin incision of only $3 \mathrm{~cm}$. All of these results are part of a system that consists of an experienced surgical staff, a safe, rapid and minimally invasive surgical technique and the usage of the latest technology in prosthesis equipment.

\section{REFERENCES}

1. Lindau ST, Schumm LP, Laumann EO, et al. A study of sexuality and health among older adults in the United States. N Engl J Med. 2007; 357:762-74.

2. Porst H, Sharlip I. History and epidemiology of male sexual dys- function. In: Porst H, Buval J, eds. Standard practice in sexual medicine. Malden, MA: Blackwell Publishing; 2006; 43-8.

3. Feldman HA, Goldstein I, Hatzichristou DG, et al. Impotence and its medical and psychosocial correlates: results of the Massachusetts Male Aging Study. J Urol. 1994; 151:54-61.

4. Mulhall JP, Bella AJ, Briganti A, et al. Erectile function rehabilitation in the radical prostatectomy patient. J Sex Med. 2010; 7:1687-98.

5. Gontero P, Fontana F, Zitella A, et al. A prospective evaluation of efficacy and compliance with a multistep treatment approach for erectile dysfunction in patients after non-nerve sparing radical prostatectomy. BJU Int. 2005; 95:359-65.

6. Bettocchi C, Palumbo F, Spilotros M, et al. Patient and partner satisfaction after AMS inflatable penile prosthesis implant. J Sex Med. 2010; 7:304-9.

7. Minervini A, Ralph DJ, Pryor JP. Outcome of penile prosthesis implantation for treating erectile dysfunction: Experience with 504 procedures. BJU Int. 2006; 97:129-33.

8. Henry GD, Wilson SK, Delk JR II, et al. Revision washout decreases penile prosthesis infection in revision surgery: A multicenter study. J Urol. 2005; 173:89-92.

9. Carson CC. Diagnosis, treatment and prevention of penile prosthesis infection. Int J Impot Res. 2003; 15(Suppl 5):S139-46.

10. Montague DK, Angermeier KW, Lakin MM. Penile prosthesis infections. Int J Impot Res. 2001; 13:326-8.

11. Carson CC. Infections in genitourinary prostheses. Urol Clin North Am. 1988; 16:139-47.

12. Wilson SK, Costerton JW. Biofilm and penile prosthesis infections in the era of coated implants; A review. J Sex Med. 2012; 9:44-53.

13. Wilson SK, Zumbe J, Henry GD, et al. Infection reduction using antibiotic-coated inflatable penile prosthesis. Urology. 2007; 70:337-40.

14. Montorsi F, Rigatti P, Carmignani G, et al. AMS three-piece inflatable implants for erectile dysfunction: a long-term multi-institutional study in 200 consecutive patients. Eur Urol. 2000; 37:50-5.

15. Perito PE. Minimally invasive infrapubic inflatable penile implant. J Sex Med. 2008; 5:27-30.

16. Mulcahy JJ, Austoni E, Barada JH, et al. The penile implant for erectile dysfunction. J Sex Med. 2004; 1:98-109.

17. Montague DK, Angermeier KW. Penile prosthesis implantation. Urol Clin North Am. 2001; 28:355-61.

18. Natali A, Olianas R, Fisch M. Penile implantation in Europe: successes and complications with 253 implants in Italy and Germany. J Sex Med. 2008; 5:1503-12.

19. Bernal RM, Henry GD. Contemporary patient satisfaction rates for three-piece inflatable penile prosthesis. Adv Urol 2012; 2012:707321.

20. Moskovic DJ, Gittens P, Avila D Jr, et al. Favorable female sexual function is associated with patient satisfaction after inflatable penile prosthesis implantation. J Sex Med. 2011; 8:1996-2001.

\section{Correspondence}

Gabriele Antonini, MD - Gian Maria Busetto, MD - Ettore De Berardins, MD Riccardo Giovannone, MD - Vincenzo Gentile, MD

Department of Gynecological-Obstetrics Sciences and Urological Sciences, Sapienza Rome University, Policlinico Umberto I, Rome, Italy

Patrizio Vicini, MD (Corresponding Author)

patriziovicini@gmail.com

Department of Urology, "I.N.I." Italian Neurotraumatologic Institute Grottaferrata, Rome, Italy

Paul E. Perito, MD

Perito Urology, Coral Gables Hospital Miami, Florida (USA) 